\section{Personality Style in Patients Looking for Tooth Bleaching and Its Correlation with Treatment Satisfaction}

\author{
Javier Martin1, Vanessa Rivas', Patricio Vildósola1, Laura Moncada², Osmir \\ B. Oliveira Junior ${ }^{3}$, José Roberto C. Saad ${ }^{3}$, Eduardo Fernandez ${ }^{1}$, Gustavo \\ Moncada ${ }^{4}$
}

\begin{abstract}
In the last years the focus in dentistry has shifted to an "esthetic dentistry" approach, where patients are concerned about reaching a better look of their teeth. Vital tooth bleaching is a technique with immediate results, which improves the appearance and patient's self-esteem. The aim of this study was to recognize personality characteristics determined by the Millon Index of Personality Styles of participants looking for tooth bleaching and to correlate them to satisfaction with the treatment. Forty participants were included and filled out the Millon Index of Personality Styles form before treatment. Expectation about tooth bleaching was quantified from 1 to 5 . Patients were treated with bleaching agent according to manufacturer's directions. One week after treatment, the patient's satisfaction was quantified from 1 to 5 . Prevailing personality characteristics were determined. Expectations and satisfaction values of all patients were correlated with each of the presented personality scales by Spearman Rho test. Ten scales prevailed over their counterpart. Median of patient's expectation was 2 and satisfaction 4. Only the score of a single characteristic (extraversing) showed statistically significant correlation with patient satisfaction. Patients looking for tooth bleaching treatment seem to have common personality characteristics. Almost all of them wanted to achieve a moderate change in teeth color and the result of the treatment was usually satisfactory
\end{abstract}

'Department of Restorative Dentistry, Dental School Universidad de Chile, Santiago, Chile ${ }^{2}$ Department of Psychology, Social Sciences Faculty, Universidad de Chile, Santiago, Chile ${ }^{3}$ Dental School, UNESP Universidade Estadual Paulista, Araraquara, SP, Brazil

${ }^{4}$ Dental School, Universidad

Mayor, Santiago, Chile

Correspondence: Javier Martín C, Sergio Livingstone Pohlhammer 943, Independencia. Santiago, Chile. Tel: +56-229781738. javmartin@gmail.com

Key Words: tooth bleaching, MIPS, expectations, satisfaction, clinical trial, personality.

\section{Introduction}

Dental appearance is an important characteristics related to facial attraction with consequences associated to self-image, social interactions and therefore to psychological health $(1,2)$. It is influenced by individual preferences and cultural and sociodemographic factors (3). When the smile is destroyed by dental diseases, the result is a loss of self-esteem and damage to physical and mental health $(4,5)$. Dental tooth color is one of the most important factors in determining satisfaction with self-appearance (6), with a particular cosmetic importance $(4,5)$.

In recent years' dentistry has shifted to a "esthetic dentistry" were patients demand a youthful, attractive smile(7). The color of teeth dissatisfies about 30\% of patients $(4,7)$. Vital tooth bleaching is a technique with immediate results, which improves the appearance and patient's self-esteem. There have been reported discrepancies between treatment needs perceived by patients and those assessed by dental professionals(8). It has been demonstrated that patient's expectations, i.e. what the patient expects of the treatment, are higher than those of dentists, they expect whiter teeth than dentists $(9,10)$, what could generate discrepancies between them. Also, as a result of bleaching treatment patients search for a monochromatic white color and a perfect dental appearance like the one seen in visual media(11) because whiter teeth are positively correlated with high levels of social competence, intellectual ability, psychological adaptation and sociability indexes $(8,12)$.

Personality is defined as the distinct style of adaptive functioning that a member of a species exhibits in coping with its environment (11). The Millon Index of Personality Styles (MIPS) is a 180 items true-false questionnaire that measures personality characteristics in normally adult individuals, i.e. patients between 18 and 65 years that do not show psychopathology. This instrument provides data on personality styles arranged according to three main dimensions: Motivating styles (the person's basic orientation toward obtaining reinforcement from the environment), thinking styles (the person's styles of information processing) and behaving styles (the person's styles of relating to others). It identifies 24 personality characteristics (or scales) (grouped in 12 bipolar pairs, i.e. scales that define opposite styles from a theoretical viewpoint) that may be present or absent in each individual. Each scale measures a different characteristic of the individual's personality and each pair includes two juxtaposed scales (11-14).

There are no studies defining personality characteristics of patients looking for bleaching treatment in the literature. 
Clinicians could benefit from understanding the common behavior of patients seeking cosmetic treatment. The aim of this study was to recognize personality characteristics determined by the Millon Index of Personality Styles of patients looking for tooth bleaching and to correlate them to satisfaction with the treatment. The first null hypothesis is that there are no common personality characteristics in people seeking tooth bleaching; a second null hypothesis is that there is no correlation with post-bleaching satisfaction.

\section{Material and Methods}

\section{Study Design}

The study was conducted to describe personality characteristics of patients looking for tooth bleaching treatment, and associate them with their expectations and satisfaction. Forty participants, between 18 and 40 years, who attended the Operative Dentistry Clinic at Dental School were included. The study was approved by the Research Office and the Ethics Board of the Dental School (FIOUCH 2013-18). Recruitment was by printed advertisement posted at the Dental School board 30 days before the beginning of the study. The inclusion criteria were anterior teeth with at least A3 color registration by VITA Classical ${ }^{\circledR}$ Shade Guide (VITA Zahnfabrik, Bad Säckingen, Germany) without previous bleaching experience. The exclusion criteria were anterior teeth with caries, restoration or cervical lesions; dental pain symptoms; pregnant or breastfeeding participants, tetracycline stains classified as 3-4 according to Jordan and Boksman (15) or fluorosis stains classified as 3 or higher according to the Thylstrup-Fejerskov Index (16); dental malocclusion or in orthodontic treatment; participants with periodontal disease or those previously diagnosed by a specialist as having psychopathology (self reported by the patient).

\section{MIPS Data Collection}

Participants were informed about the study and signed an informed consent form. Before bleaching treatment, each patient answered the MIPS form. Each patient received a copy of the questionnaire and an answers sheet where he/she marked true or false according to each test assertion. A psychologist explained how to answer the test and controlled the required time (30 $\mathrm{min}$ ) to finish it. The psychologist did not interfere in the process but stayed near to clarify any doubt of the patient.

The MIPS is a questionnaire with 180 assertions. For each of them, the subject must decide if it represents him or not (answering true or false). It is used to measure personality characteristics of patients between 18 and 65 years that do not exhibit psychopathology (12). This inventory evaluates dimensions of interpersonal traits and styles distinctive of normal population. The opposite characteristics that constitute a trait are called scales (12). The questionnaire comprises 24 scales grouped in twelve pairs. Each scale measures a distinct feature of an individual's personality and each pair includes two juxtaposed scales. The twelve pairs of MIPS scales are grouped into three major areas: motivational goals, cognitive modes and interpersonal behavior.

Motivational goals cover desires or goals that encourage and guide humans to act in a specific way according to their purposes. The included three pairs of scales are (a) enhancing (patients that tend to look on the bright side of things, optimistic about the possibilities offered by the future)/preserving (focus on life problems and worsens them, always seem to be waiting for something to go wrong); (b) modifying (try to change their environment and events so they meet their needs and desires)/ accommodating (place little effort to manage or change their life); (c) individuating (oriented in meeting their own needs and desires, independent and self-centered)/ nurturing (motivated to first meet other's needs, looking the welfare of others before their own)(12).

The four pairs of scales in cognitive modes include both the sources used to gain life knowledge and the way to transform this information. They are (a) extraversing (look for others in pursuit of stimulation and encouragement; friends and colleagues are sources of ideas and guidance)/ introverting (use their own thoughts and feelings as a resource, their main source of inspiration and stimulation are themselves); (b) sensing (their knowledge is derived from tangible and concrete phenomena rather than using inference and abstraction)/intuiting (prefer the symbolic and unknown to the concrete and observable, enjoying most mysterious experiences and speculative knowledge sources); (c) thinking (process the knowledge through logic and analytical reasoning; their decisions are based on dispassionate, impersonal and objective judgments)/feeling (their judgments are formed taking into consideration their emotional reactions to circumstances, subjectively evaluating their consequences); (d) systematizing (very organized and predictable in their approach to life experiences; are considered orderly, meticulous and efficient)/innovating (tend to be creative and risk takers, are ready to change and rearrange anything; they seem dissatisfied with the routine and the predictable) (12).

The five pairs of scales included in interpersonal behaviors consider different ways of relating to others. They are (a) retiring (they lack emotionality and are socially indifferent, silent, passive and reluctant to take part)/ outgoing (seek stimulation and attention); (b) hesitating (shy, experiencing anxiety in social situations, they want to be accepted but often fear that others will reject them)/ asserting (believe they are more competent and talented 
than those around; ambitious, self-centered and secure in themselves); (c) dissenting (act independently and in a non-conformist way; refuse to abide traditional rules)/ conforming (honest and self-controlled, respectful and cooperative, tend to act formal and with good manners in social situations); (d) yielding (habituated more to suffering than pleasure, are submissive and tend to bow to others; their behavior prevents them from succeeding even possessing the required abilities)/controlling (strong and dominant, socially aggressive); (e) complaining (passiveaggressive, moody and generally feeling unsatisfied)/ agreeing (socially sympathetic, showing receptive in their relations, hiding negative feelings, especially when they may be objectionable to people they want to please) (12).

According to the answers, each scale may get a score between 0 and 100. A scale present in a patient must have a minimum score of 50 . Scores under 50 indicate that the scale is not present. Scores over 50 show presence of the scale in different levels. Thus, a scale is slightly present when it has a score between 50 and 59 and the difference between this score and the score of the opposite scale of the pair is a positive value. A scale is considered moderately present when it gets a score between 60 and 69 and the difference values over 50 ) and the absolute difference between their scores is less than 6, the patient is described as "balanced" in these scales (17).

\section{Expectation and Satisfaction Data Collection}

Treatment expectation was determined asking the patient to mark from 1 to 5 what he/she expected of tooth bleaching treatment, 1 being "slightly whiter teeth" and 5 "extremely whiter teeth". All patient's anterior teeth were bleached (maxillary and mandibular) and one week after treatment, patient's satisfaction was recorded quantifying it by marking from 1 to 5 how satisfied he/she was with the bleaching treatment, 1 being "not satisfied" and 5 "extremely satisfied".

\section{Statistical Analysis}

MIPS data were entered in a Microsoft Excel data sheet and analyzed by a psychologist blind to patient's expectations and satisfaction. For each patient was determined which scales were present and the number of participants that presented each scale was determined. For each pair of opposite scales was determined if any of them predominated over its counterpart by Wilcoxon rank test. Also, the mean score value of each scale was determined to define the level to which it was present.

Expectations and satisfaction values of all participants were quantified and correlated with each of the presented personality scales by Spearman Rho test (SPSS v.15). In all tests, the level of confidence was set at $p=0.05$.

\section{Results}

All participants were evaluated one week after treatment. 35\% of participants $(n=14)$ were male and $65 \%(n=26)$ female. Mean age was $22.73 \pm 3.27$, with all participants between 18 and 37 years.

\section{Patient's Expectation and Satisfaction}

Median patient's expectation was 2, with $52.5 \%$ of participants choosing option 2 and median satisfaction 4 , with 67.5\% choosing this option (Table 1).

\section{Personality Characteristics of Participants}

Related to personality scales, 10 of them prevailed over its counterpart. In motivating styles dimension, the number of participants that presented the scales enhancing $(n=36)$, modifying $(n=31)$ and individuating $(n=23)$ predominated over participants that presented preserving $(n=2, p=0.000)$, accommodating $(n=5, p=0.000)$ and nurturing $(n=10$, $\mathrm{p}=0.019$ ) scales respectively.

In thinking styles dimension, participants that presented extraversing $(n=32)$ and systematizing $(n=21)$ scales prevailed over those who presented introverting $(n=6$, $p=0.000)$ and innovating $(n=9, p=0.003)$ respectively. 2 pairs of scales (sensing ( $n=20)$-intuiting $(n=13)$ and thinking ( $n=22)$-feeling $(n=13))$ were equally present in all participants ( $p=0.157$ and $p=0.480$ respectively)

In behaving styles dimension the number of participants that presented outgoing $(n=28)$, asserting $(n=33)$, conforming $(n=30)$, controlling $(n=24)$ and agreeing $(n=23)$ scales predominated over those presenting retiring $(n=4$, $p=0.000)$, hesitating $(n=3, p=0.000)$, dissenting $(n=2$, $p=0.000)$, yielding $(n=4, p=0.000)$ and complaining $(n=2$, $\mathrm{p}=0.000$ ) respectively.

No correlation was found between patient's expectations and the score of any scale. Satisfaction about bleaching treatment was only correlated to one MIPS scale (extraversing) (Rho $=0.352, \mathrm{p}=0.026$ ).

\section{Discussion}

In present study, expectations with tooth bleaching showed that patients wanted to obtain a moderate change of their teeth color, as most of them (52\%) marked option 2. Tin-0o (6) and Dudea (18) reported that in general, people want to get whiter teeth, but the perception of dental and facial attractiveness is a subjective and difficult topic to discuss $(6,18)$. 
All participants showed a change in teeth color, with a mean $\Delta$ E value of 3.76 (ranging from 1.8 to 7.2 ). Satisfaction perceived after treatment was considered high since most participants were highly satisfied. Dental literature has not established how much color difference is perceivable to observers, but in a review by Khashayar et al. (19) it was concluded that a color difference of $\Delta \mathrm{E}=1$ may be the threshold at which $50 \%$ of observers would detect a change in color(19). This change in color could be enough to satisfy the patients as they search for "normality" and "cleanliness" more than to the perfect dental color that the professional tries to create. Patients tend to feel their appearance is normal and not that it reached some ideal of beauty(20). The important contribution of tooth color to patient's satisfaction with dental appearance is highlighted by Tin-Oo et al. (6) and Samorodnitzky-Naveh et al. (21). They found that tooth bleaching was the esthetic treatment most desired by patients, with bleached teeth associated to greater attractiveness (22).

Regarding personality characteristics, studies showed that facial attractiveness is associated to psychological characteristics as extroversion, confidence/self-esteem (23). Other studies have shown that it is correlated with personality traits such as dominance, emotional stability, inhibition, anxiety, health or self-esteem(24). Dong et al. concluded that there is correlation between the attractiveness of the smile and the personality characteristics of extroversion and low anxiety(25).

Davis (20) suggested that there are no personality factors responsible for patients seeking esthetic dental treatment. According to the present results, it is possible to distinguish common personality characteristics in patients of tooth bleaching treatment, with different levels of presence. Three strongly present characteristics were: enhancing, modifying and asserting. These are patients that look at the bright side of things, optimistic about the possibilities offered by the future and those that try to change their environment to meet their needs and desires. They also believe they are more competent and talented than those around, ambitious, self-centered and secure in themselves. Four scales were moderately present:

Table 1. Expectation and satisfaction scores of patients

\begin{tabular}{lccccc}
\hline \multirow{2}{*}{ Score } & \multicolumn{2}{c}{ Expectations } & & \multicolumn{2}{c}{ Satisfaction } \\
\cline { 2 - 3 } \cline { 5 - 6 } & $\mathrm{n}$ & $\%$ & & $\mathrm{n}$ & $\%$ \\
\hline 1 & 4 & $10.00 \%$ & & 1 & $2.50 \%$ \\
2 & 21 & $52.50 \%$ & & 2 & $5.00 \%$ \\
3 & 12 & $30.00 \%$ & & 10 & $25.00 \%$ \\
4 & 3 & $7.50 \%$ & & 27 & $67.50 \%$ \\
5 & 0 & $0.00 \%$ & & 0 & $0.00 \%$ \\
\hline
\end{tabular}

extraversing, systematizing, outgoing and conforming, which means they look for others in pursuit of stimulation and encouragement, organized and predictable in their approach to life experiences, seek for stimulation and attention and are honest and self-controlled, respectful and cooperative. Finally, three characteristics were slightly present: individuating, controlling and agreeing, which means patients oriented to meeting their own needs and desires (self-centered), strong and dominant who are socially sympathetic (receptive in their relations).

Based on these characteristics one could infer that the treated subjects are motivated to actively seek stimuli that help them meet their own needs first and to enrich their life, making it more interesting, cheerful and encouraging, achieving what they find satisfying and fulfiller, but without neglecting the context in which they are. They take charge of their life, shaping the world and making things happen. They look at the bright, optimistic side of life basically motivated by positive reinforcement $(11,12)$

Referring to their cognitive modes, they are based on the external, both in other people and in the tangible facts they can perceive by their senses. In this way, they would replace their feelings and emotions, making greater use of rational logic, which would lead to order and systematize the knowledge they get, adapting them to those whom they already count upon (12).

Finally, they are people with a strong orientation to the external, including the social area, as they need to be seen by others, entailing several edges. First, they develop good social tools, forming strong loyalties, used to get external recognition, showing themselves as outgoing and friendly. They are extroverted, highly sociable and charming, but sometimes demanding, socially aggressive and manipulative. At the same time, they have a strong sense of authority, which makes them respectful and attached to the rules. However, they have a degree of empathy that allows them to reach agreements with people, which in the end result in good social outcomes $(11,12)$.

In this study no characteristic was found to be correlated to patient's expectations with the treatment. In contrast, one characteristic (extraversing) was correlated with satisfaction with the treatment. This may be explained as extroverted people refer to others to find stimulation and encouragement; they need to participate with other people and follow them in their actions.(12) Therefore, it might be inferred that highly sociable patients may be more satisfied with the tooth bleaching outcome. According to Kershaw et al.(22), whiter teeth are correlated with high levels of social competence, intellectual ability, emotional and psychological equilibrium (22). Beall (26) reported that people with esthetic treatments are seen by others as happier, more interesting and intelligent than people 
who keep their original smiles. This can be a cause for the search for esthetic treatments, like tooth bleaching (26).

These results offer useful information to understand the patients who look for tooth bleaching (21) and to know in advance the psychological characteristics that may influence the satisfaction with the treatment outcome, which is an important aspect to consider when planning a successful treatment (6). Davis et al. evaluated the psychological effects of an esthetic dental treatment. They found that patients expected to feel less inhibited, happier, safer of themselves and improve their participation in social environments (20). From the above, one could conclude that people looking for tooth bleaching wish to improve those features with the treatment outcome.

One limitation of this exploratory study is that it did not have a control group that would help to clarify differences between groups of people who show interest in seeking cosmetic treatments and those who are not interested. However, it tries to present a research not explored in dentistry. According to this study, there are some common characteristics of the studied group of patients, so our first null hypothesis was rejected. Nevertheless, it was found no correlation with satisfaction, so the second null s hypothesis was accepted. As a further perspective, it would $\checkmark$ be interesting to increase the study sample or use another personality survey shorter and simpler that measures the five big personality traits (NEO-PI, NEO-FFI) and correlated with the data obtained by MIPS.

Within the limitations of this study, it may be concluded that patients looking for tooth bleaching treatment seem to have common personality characteristics that encourage them to look for this treatment. Almost all patients wanted to have a moderate change in teeth color that may be achieved after a single application of a bleaching agent, with the result of the treatment being usually satisfactory.

\section{Resumo}

Ultimamente, o foco da Odontologia deslocou-se para uma "odontologia estética", em que os pacientes se preocupam em conseguir uma aparência melhor para seus dentes. 0 branqueamento vital é uma técnica com resultados imediatos que melhora aparência e auto-estima do paciente. 0 objetivo deste estudo foi detectar características de personalidade definidas pelo Índice Millon de Estilos de Personalidade de pessoas que buscaram branqueamento dental e correlacioná-las com a satisfação com o tratamento. Foram incluídos 40 participantes que preencheram o formulário do Índice Millon de Estilos de Personalidade antes do tratamento. A expectative sobre o branqueamento dental foi quantificada com valores de 1 a 5 . Os pacientes foram tratados com agente branqueador de acordo com as instruções do fabricante. Uma semana depois o tratamento, a satisfação do paciente foi quantificada com valores de 1 a 5. Foram determinados as características predominantes. Os valores da expectativa e da satisfação foram correlacionados com cada escala de personalidade apresentada através do teste de Spearman Rho. Dez escalas prevaleceram sobre a sua contrapartida. A mediana das expectativas foi 2 e das satisfações foi 4.0 valor de uma caracteristica apenas (extraversão) apresentou correlação estatisticamente significante com a satisfação do paciente. Os pacientes que buscam o branqueamento dental parecem ter características comuns de personalidade. Quase todos queriam conseguir uma mudança moderada na cor dos dentes e o resultado do tratamento foi geralmente satisfatório.

\section{References}

1. Jamieson LM, Mejía GC, Slade GD, Roberts-Thomson KF. Risk factors for impaired oral health among 18- to 34-year-old Australians. J Public Health Dent 2010 Jan;70:115-123.

2. Thompson L, Malmberg J, Goodell N, Boring R. The distribution of attention across a talker's face. Discourse Process 2004;38:145-168.

3. Akarslan ZZ, Sadik B, Erten H, Karabulut E. Dental esthetic satisfaction, received and desired dental treatments for improvement of esthetics. Indian J Dent Res 2009;20:195-200.

4. Ingber FK. You are never fully dressed without a smile. J Esthet Restor Dent 2006;18:59-60.

5. Watts A, Addy M. Tooth discolouration and staining: a review of the literature. Br Dent J 2001;190:309-316.

6. Tin-Oo MM, Saddki N, Hassan N. Factors influencing patient satisfaction with dental appearance and treatments they desire to improve aesthetics. BMC Oral Health 2011;11:6.

7. Goyal MK, Goyal S, Hegde V, Balkrishana D, Narayana Al. Recreating an esthetically and functionally acceptable dentition: a multidisciplinary approach. Int J Periodontics Restorative Dent 2013;33:527-532.

8. Locker D, Slade G. Association between clinical and subjective indicators of oral health status in an older adult population. Gerodontology 1994;11:108-114.

9. Carlsson GE, Wagner I V, Odman P, Ekstrand K, MacEntee M, Marinello $C$, et al.. An international comparative multicenter study of assessment of dental appearance using computer-aided image manipulation. Int J Prosthodont 1998;11:246-254.

10. Wagner IV, Carlsson GE, Ekstrand K, Odman P, Schneider N. A comparative study of assessment of dental appearance by dentists, dental technicians, and laymen using computer-aided image manipulation. J Esthet Dent 1996;8:199-205.

11. Robin AL, Tzelepis A, Bedway M. A cluster analysis of personality style in adults with ADHD. J Atten Disord 2008;12:254-263.

12. Millon T. MIPS. Inventario Millon de Estilos de Personalidad. Primera Ed. Buenos Aires: PAIDOS; 1997.

13. Piersma HL, Ohnishi $H$, Lee DJ, Metcalfe WE. An empirical evaluation of Millon's dimensional polarities. J Psychopathol Behav Assess 2002;24:151-158.

14. Martín-Brufau R, Corbalán-Berná J, Ramirez-Andreo A, BrufauRedondo C, Limiñana-Gras R. Personality differences between patients with lichen simplex chronicus and normal population: A study of pruritus. Eur J Dermatology 2010;20:359-363.

15. Jordan RE, Boksman L. Conservative vital bleaching treatment of discolored dentition. Compend Contin Educ Dent 1984;5:803$805,807$.

16. Thylstrup A, Fejerskov 0. Clinical appearance of dental fluorosis in permanent teeth in relation to histologic changes. Community Dent Oral Epidemiol 1978;6:315-328.

17. Moncada L, Dreyer E, Llanos G, Rios M, Santana R. Personality Styles Differences Amongst Adult's Centric and Eccentric Bruxers. Preliminary Report. Rev Clin Periodoncia Implant Rehabil Oral 2008;3:1-4.

18. Dudea D, Lasserre J-F, Alb C, Culic B, Pop Ciutrila IS, Colosi H. Patients' perspective on dental aesthetics in a South-Eastern European community. J Dent 2012;40 Suppl 1:e72-e81.

19. Khashayar G, Bain PA, Salari S, Dozic A, Kleverlaan CJ, Feilzer AJ. Perceptibility and acceptability thresholds for colour differences in dentistry. J Dent 2014;42:637-644.

20. Davis LG, Ashworth PD, Spriggs LS. Psychological effects of aesthetic dental treatment. J Dent 1998;26:547-554.

21. Samorodnitzky-Naveh G, Geiger S, Levin L. Patients' satisfaction with dental esthetics. J Am Dent Assoc 2007;138:805-808.

22. Kershaw $\mathrm{S}$, Newton JT, Williams DM. The influence of tooth colour on the perceptions of personal characteristics among female dental 
patients: comparisons of unmodified, decayed and "whitened" teeth. Br Dent J 2008;204:E9; discussion 256-257.

23. Van der Geld P, Oosterveld P, Van Heck G, Kuijpers-Jagtman AM. Smile attractiveness. Self-perception and influence on personality. Angle Orthod 2007;77:759-765.

24. Feingold A. Good-looking people are not what we think. Psychol Bull 1992;111:304-341
25. Dong JK, Jin TH, Cho HW, Oh SC. The esthetics of the smile: a review of some recent studies. Int J Prosthodont 1999;12:9-19.

26. Beall AE. Can a new smile make you look more intelligent and successful? Dent Clin North Am 2007;51:289-297.

Received April 17, 2014 Accepted December 16, 2015 